\title{
Pattern and Trend of Night Land Surface Temperature in Africa
}

\author{
Cherdchai Me-ead ${ }^{1} \&$ Rhysa McNeil ${ }^{1,2^{*}}$ \\ This study aims to identify patterns and trends of the night land surface temperature over eight day \\ period from 2000 to 2014 in Africa using statistical analysis. Data were obtained from the United States \\ National Aeronautics and Space Administration satellite, comprising 99 locations of $5^{\circ}$ by $5^{\circ}$ latitude \\ and longitude grid-boxes between latitudes $35^{\circ}$ north and south of the equator and longitudes $20^{\circ}$ \\ west to $50^{\circ}$ east. First, the variation in the night surface temperatures was removed. Then, the trend \\ of seasonally adjusted night temperatures was estimated using linear regression. The correlations \\ between adjoining regions were considered by using factor analysis to classify the temperatures into \\ four regions. Cubic spline models were fitted to the data within these regions to investigate patterns \\ of the temperatures. The result showed that temperatures in most regions of Africa increased. The \\ temperatures decreased was observed in southern Africa and parts of central and eastern Africa.
}

Climate change is a major environmental problem affecting all countries. In recent years, increased temperatures have caused changes in sea levels, destruction of ecosystems, shrinkage of mountain glaciers, reduction of ice cover ${ }^{1}$ and altered ocean circulation patterns ${ }^{2}$. Moreover, climatic variability is associated with the El Niño Southern Oscillation and natural disasters ${ }^{3}$.

Numerous studies have shown variations in climate and associated changes in temperature in Africa ${ }^{4-7}$. Africa lies in tropical and subtropical latitudes; the temperatures are considerably high throughout the year and vary from day to night. In more than a third of the continent, the annual temperature range is less than $6^{\circ} \mathrm{C}$. Temperatures are relatively constant from year to year except in the highest latitudes. A cold season arose at the poleward extremes of the north of the Sahara and areas of southern Africa ${ }^{6}$. The continent of Africa has been warmer than 100 years ago. Global warming was about $0.5^{\circ} \mathrm{C}$ over the 20 century ${ }^{8}$.

Several studies have investigated the trends of temperature in Africa. During 1960 to 1990, on average the maximum temperatures increased by $0.11^{\circ} \mathrm{C}$ per decade and $0.12{ }^{\circ} \mathrm{C}$ per decade for non-urban and urban stations, respectively ${ }^{9}$. The average surface minimum and maximum air temperatures of 71 stations from 1939 to 1992, over eastern Africa were varied, mostly for the stations close to a large water feature ${ }^{10}$.

The climates of Africa range from humid equatorial regions to seasonally arid tropical regions and subtropical. The climates have differing degrees of temporal variability, with regard to rainfall. Assessing and estimating the spatial and temporal variation in temperature is crucial for climate science and for designing environmental programs ${ }^{8}$. This study considers night time observations to reduce the scale mismatch issue between point ground measurements and the MODIS footprint. A series of satellite pixels of Africa can be used to provide the data of temperature changes of the region, both days and nights. During the night, the earth's surface is quite homogeneous surface. During the day, surface temperatures under shadows are lower than surface temperatures in direct sunlight, the temperature differences of about $20^{\circ} \mathrm{C}^{11}$. Therefore, with this view and importance, this study investigated the trends and patterns of night land surface temperatures over eight day periods from 2000-2014 in Africa using appropriate statistical methods.

\section{Materials and Methods}

Data management and study areas. The study area is between latitudes $35^{\circ}$ north and south and longitudes $20^{\circ}$ west to $50^{\circ}$ east, covering the entire African continent. This study used Moderate Resolution Imaging Spectroradiometer (MODIS) data which observed by NASA's satellite. MODIS measures climate variables such as land surface temperature on and above the Earth's surface by decoding solar reflectance images viewed by an Earth-orbiting satellite.

The night time land surface temperatures were stored as integers. MODIS is used to capture pictures of the Earth overtime at the same location. It records satellite pixels for every eight days and provided them publicly

${ }^{1}$ Faculty of Science and Technology, Prince of Songkla University, Pattani, Thailand. ${ }^{2}$ Centre of Excellence in Mathematics, Commission on Higher Education (CHE), Ministry of Education, Ratchathewi, Bangkok, 10400, Thailand. *email: nittaya.ch@psu.ac.th 


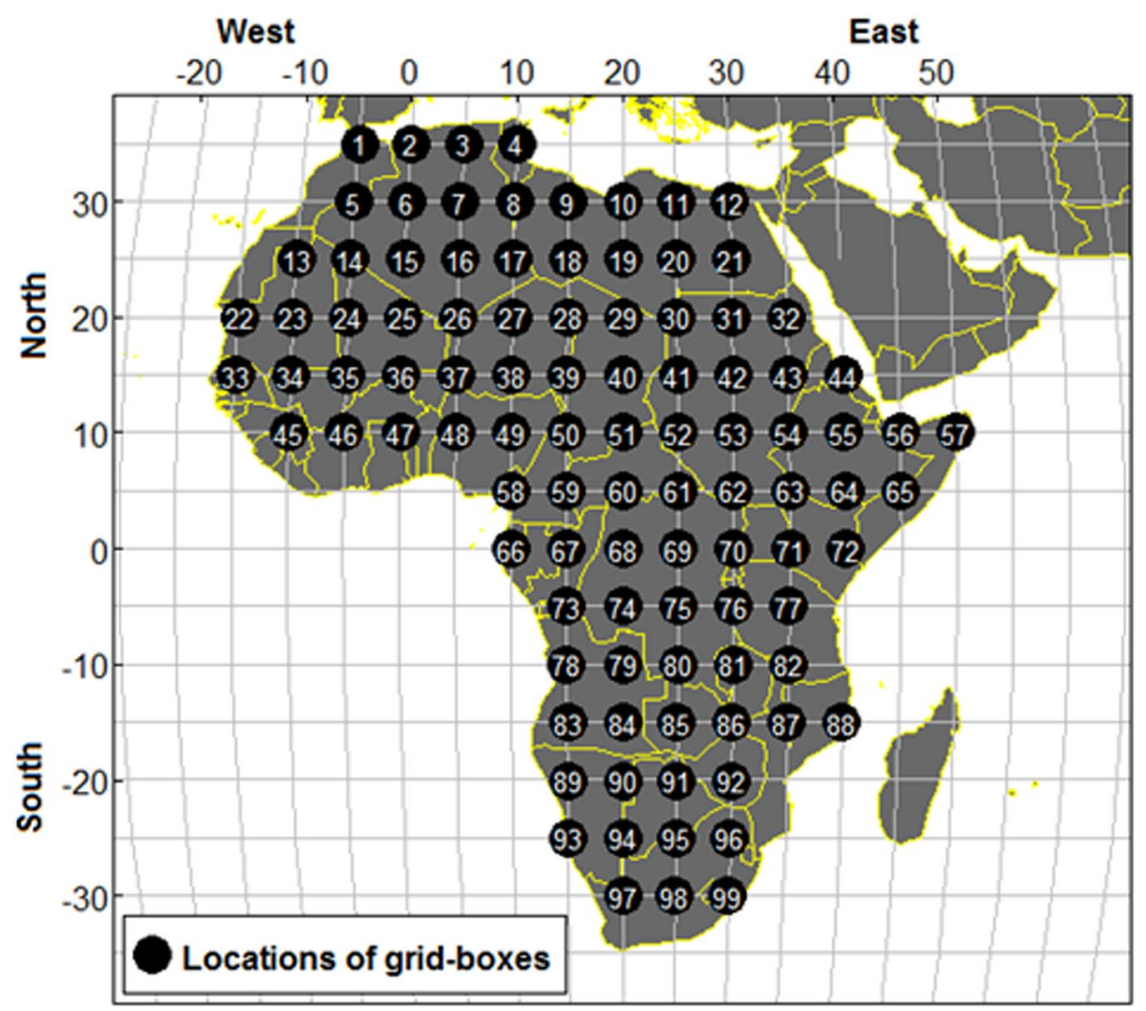

Figure 1. Map of the study area showing 99 locations of satellite image by NASA satellite ( 5 latitude by 5 longitude).

between 2000 to 2014. These pixels can be converted into temperatures from their color index. The temperatures are divided by 50 to obtain degrees Kelvin ${ }^{12}$, and subtracting 273.15 to obtain the equivalent degrees Celsius. Zeroes relate to missing data due to insufficient measurement quality. This can occur when water vapor and/ or cloud are in the line of sight. The data has 668 records corresponding to the days when the satellite recorded images for this region. The period between each such observation is slightly less than eight days because each year has 46 observations for the same region. The series of satellite pixels of Africa can be used to provide the data of temperature changes of the region. The night temperature data for 15 years were obtained from the website (http://daac.ornl.gov/cgi-bin/MODIS/GLBVIZ_1_Glb/modis_subset_order_global_col5.pl) for 99 point locations of $5^{\circ}$ by $5^{\circ}$ latitude-longitude grid-boxes ( 81 square kilometers per point location) in Africa. Thus, there were 99 point locations for the analysis as shown in Figure 1.

Statistical methods. The variation in temperatures for every eight day period was removed by subtracting the average temperature in each period and adding back the overall mean of the 99 locations. It takes the form:

$$
y_{i j}=\left(x_{i j}-\bar{x}_{. j}\right)+\bar{x}_{. .}
$$

where $y_{i j}$ is the seasonally adjusted night land surface temperatures for every eight day period at year $i$ for period $j, x_{i j}$ is the night land surface temperatures for every eight day period at year $i$ for period $j, \bar{x}_{. j}$ is the average of period $j$ over 15 years and $\bar{x}$.. is the overall mean.

A linear regression method ${ }^{13}$ is arguable one of the most widely used parametric test in trend detention in climate science. The application of linear regression in trend analysis includes sea surface temperature trends ${ }^{14}$ and rainfall trends ${ }^{15}$ was applied to the seasonally adjusted night surface temperature changes in an eight day period for each of the 99 locations in Africa. The model takes the form:

$$
y_{i j k}=m_{k}+a_{i k}+b_{j k}
$$

for $i=1,2,3, \ldots, 15, j=1,2,3, \ldots, 46$ and $k=1,2,3, \ldots, 99$ where $y_{i j k}$ denotes the seasonally adjusted night surface temperature of the eight day period in the year $i$ for period $j$ and at location area $k, m_{k}$ is a constant for location area $k$, and the terms $a_{i k}$ and $b_{j k}$ are estimated coefficients for year $i$ and period $j$, respectively.

The night land surface temperatures in the 99 locations were grouped into regions to account for the correlation between adjoining regions using factor analysis ${ }^{16}$. Factor analysis is arguably one of the mostly used method to reduce a set of correlated variables into a smaller set of uncorrelated variables by combining variance in highly mutually correlated subgroups, preferably with minimal loss of information ${ }^{14,15}$. The model with $p$ factors takes the form: 


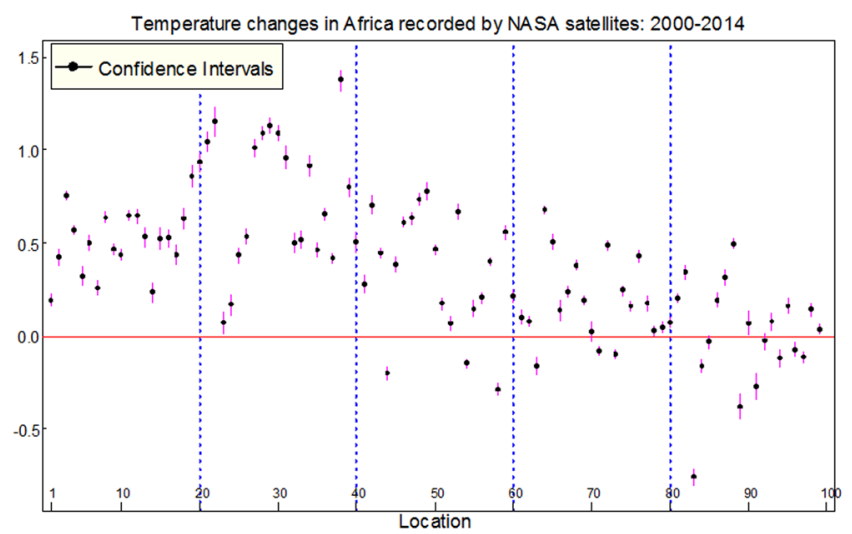

Figure 2. Estimates and $95 \%$ confidence intervals for land surface temperature changes at night in Africa from 2000-2014.

$$
y_{k j}=\mu_{k}+\sum_{p=1}^{m} \lambda_{k p} \phi_{k p},
$$

where $k=1,2,3, \ldots, 99, j=1,2,3, \ldots, 46$ and $p=1,2,3, \ldots, m$ and $y_{k j}$ is the average land surface temperature in an eight day period at location $k$ for period $j ; \mu_{k}$ is the average across 46 months for the location $k ; \lambda_{k p}$ is the factor loadings at $k^{\text {th }}$ location on $p^{\text {th }}$ factor; and, $\phi_{k p}$ is $p^{\text {th }}$ common factor for location $k$.

This information was expressed as the proportion of variance in the data accounted for by the factor analysis. A set of loadings gives measures of the extent to which each of the original variables correlates with each factor. The loadings (usually between -1 and 1 ) were controlled using Promax rotation, to make these loadings as close to 0 or 1 as possible. The loading factors of more than 0.33 were used as the criteria to classify regions in each factor ${ }^{17}$. A spline function is a piecewise cubic polynomial with continuous second derivatives, and is smoothest among all functions in the sense that it has minimal integrated squared second derivative. It is fitted using linear least squares regression. The end of every year is followed by the beginning of the next year and so the model is a smooth periodic function within the annual connection points for the whole 15 year period. The connection points are known as knots. The most appropriate model is a cubic spline with boundary conditions ensuring smooth periodicity. The formula for cubic spline function takes the form ${ }^{18,19}$ :

$$
S(t)=a+b t+\sum_{r=1}^{q} c_{r}\left(t-t_{r}\right)_{+}^{3},
$$

where, $S(t)$ is the spline function of the data, $a, b$ and $c$ are the constants. $r$ is the locations of the knots starting from $1, q$ is the total number of knots, $t$ denotes time, $t_{1}<t_{2}<\ldots<t_{q}$ are specified knots and $(t-x)_{+}$is $t-x$ for $t>x$ and 0 otherwise. An advantage of the use of cubic spline function in modelling is its ability to handle a significant amount of missing data.

Graphical and statistical displays were created using $\mathrm{R}^{20}$.

\section{Result and Discussion}

The results of linear regression model provided temperature changes and their $95 \%$ confidence interval for 99 locations in Africa as displayed in Figure 2. Eighty-one locations showed a significant temperature increase, 12 locations show a significant decrease and 6 locations showed no change. The maximum increase in temperature was observed at latitude $15^{\circ} \mathrm{N}$ and longitude $10^{\circ} \mathrm{E}$ with an increment of $1.38^{\circ} \mathrm{C}$ and the minimum increase was observed at latitude $10^{\circ} \mathrm{S}$ and longitude $15^{\circ} \mathrm{E}$ and also at latitude zero and longitude $30^{\circ} \mathrm{E}$ with an increment of $0.03^{\circ} \mathrm{C}$. The maximum decrease in temperature was found at latitude $15^{\circ} \mathrm{S}$ and longitude $15^{\circ} \mathrm{E}$ with the decrement of $0.76^{\circ} \mathrm{C}$, while the minimum decrease in temperature was found at latitude $20^{\circ} \mathrm{S}$ and longitude $30^{\circ} \mathrm{E}$ and also at latitude $15^{\circ} \mathrm{S}$ and longitude $25^{\circ} \mathrm{E}$ with a decrement of $0.03^{\circ} \mathrm{C}$, respectively. Assessment of the autocorrelation graphs did not show any significant serial correlation, which might revealed worse of fit of the models.

The correlation between night temperatures at eight day intervals between pixels $1 \mathrm{~km}$ apart in the 99 locations ranged from 0.00004 to 0.89948 . Factor analysis classified the temperatures into regions (factors) by considering the value of the factor loadings. Table 1 shows the factor loadings in ascending order within each factor and uniqueness value. Four factors were identified. Factor 1 consists of 26 locations, factor 2 consist of 22 locations, factor 3 consist of 17 locations and factor 4 consist of 16 locations. Seven locations (locations 38, 39, 43, 53, 56, 57 and 95) had mixed factors, while 18 locations were considered unique to others. Thus, region with uniqueness value above 0.78 and loading below 0.3 and negative loading were omitted from further analysis. Figure 3 displays a map of Africa and the four regions as identified by the factor model. The 99 locations are represented by the circles and coded from factor 1 to factor 4 . Eleven locations are represented by an empty circle (darkest shade) representing high uniqueness regions and could not be classify into any region. This model accounted for $48.4 \%$ of the total variance in the night temperatures. 


\begin{tabular}{|c|c|c|c|c|c|}
\hline Temp & Factor 1 & Factor2 & Factor3 & Factor4 & Uniqueness \\
\hline 7 & 0.97 & -0.12 & & & 0.16 \\
\hline 14 & 0.97 & & & & 0.18 \\
\hline 4 & 0.96 & & & & 0.22 \\
\hline 6 & 0.96 & -0.12 & & & 0.16 \\
\hline 15 & 0.96 & & & & 0.17 \\
\hline 5 & 0.95 & -0.11 & & & 0.17 \\
\hline 8 & 0.95 & & & & 0.17 \\
\hline 3 & 0.95 & -0.10 & & & 0.19 \\
\hline 9 & 0.95 & & & & 0.19 \\
\hline 13 & 0.93 & & & & 0.24 \\
\hline 2 & 0.91 & & & & 0.27 \\
\hline 16 & 0.91 & & & & 0.17 \\
\hline 17 & 0.89 & & & & 0.17 \\
\hline 10 & 0.88 & & & & 0.25 \\
\hline 1 & 0.85 & & & & 0.33 \\
\hline 23 & 0.84 & & & & 0.27 \\
\hline 18 & 0.83 & & & & 0.19 \\
\hline 24 & 0.83 & & 0.11 & & 0.24 \\
\hline 19 & 0.74 & & 0.16 & & 0.22 \\
\hline 25 & \begin{tabular}{|l|}
0.64 \\
\end{tabular} & & 0.25 & & 0.32 \\
\hline 29 & 0.63 & & 0.25 & -0.11 & 0.25 \\
\hline 28 & 0.63 & & 0.26 & -0.13 & 0.23 \\
\hline 27 & 0.63 & & 0.27 & -0.11 & 0.24 \\
\hline 26 & 0.61 & & 0.28 & & 0.28 \\
\hline 22 & 0.58 & & 0.21 & & 0.46 \\
\hline 98 & 0.46 & & -0.20 & 0.33 & 0.33 \\
\hline 21 & -0.15 & 0.98 & & & 0.14 \\
\hline 20 & -0.15 & 0.98 & & & 0.14 \\
\hline 30 & -0.15 & 0.96 & & & 0.19 \\
\hline 31 & -0.15 & 0.93 & & & 0.23 \\
\hline 11 & -0.12 & 0.92 & & & 0.19 \\
\hline 12 & -0.13 & 0.91 & & & 0.20 \\
\hline 41 & & 0.80 & & -0.12 & 0.40 \\
\hline 42 & -0.13 & 0.79 & & & 0.41 \\
\hline 94 & & 0.75 & & & 0.40 \\
\hline 32 & & 0.74 & & & 0.44 \\
\hline 97 & & 0.74 & & -0.14 & 0.40 \\
\hline 90 & -0.16 & 0.63 & & -0.10 & 0.53 \\
\hline 89 & -0.10 & 0.62 & & -0.22 & 0.53 \\
\hline 88 & -0.11 & 0.59 & & -0.17 & 0.59 \\
\hline 44 & & 0.58 & -0.13 & -0.11 & 0.64 \\
\hline 52 & 0.12 & 0.55 & -0.12 & -0.24 & 0.59 \\
\hline 82 & -0.10 & 0.53 & & & 0.68 \\
\hline 93 & & 0.51 & & -0.28 & 0.60 \\
\hline 72 & -0.15 & 0.45 & & -0.42 & 0.57 \\
\hline 87 & -0.28 & 0.42 & & -0.14 & 0.69 \\
\hline 43 & & 0.38 & -0.19 & -0.34 & 0.76 \\
\hline 55 & 0.13 & 0.35 & & -0.29 & 0.75 \\
\hline 50 & & & 0.73 & & 0.47 \\
\hline 49 & & & 0.71 & -0.12 & 0.45 \\
\hline 36 & & 0.13 & 0.70 & & 0.42 \\
\hline 48 & -0.11 & & 0.69 & & 0.60 \\
\hline 34 & & & 0.67 & & 0.53 \\
\hline 47 & & & 0.66 & & 0.61 \\
\hline 35 & 0.13 & & 0.65 & & 0.46 \\
\hline 51 & & & 0.64 & & 0.54 \\
\hline
\end{tabular}




\begin{tabular}{|c|c|c|c|c|c|}
\hline Temp & Factor1 & Factor2 & Factor3 & Factor4 & Uniqueness \\
\hline 40 & 0.11 & & 0.64 & -0.13 & 0.44 \\
\hline 46 & & & 0.63 & & 0.64 \\
\hline 33 & & & 0.61 & & 0.61 \\
\hline 37 & 0.23 & 0.13 & 0.60 & & 0.39 \\
\hline 45 & & & 0.56 & & 0.67 \\
\hline 38 & 0.35 & 0.11 & 0.48 & -0.13 & 0.35 \\
\hline 39 & 0.39 & & 0.45 & -0.13 & 0.35 \\
\hline 57 & 0.37 & & 0.40 & -0.13 & 0.44 \\
\hline 56 & 0.38 & & 0.39 & & 0.47 \\
\hline 85 & & & & 0.78 & 0.40 \\
\hline 86 & & 0.13 & & 0.74 & 0.44 \\
\hline 84 & & & & 0.74 & 0.43 \\
\hline 80 & & & 0.13 & 0.68 & 0.62 \\
\hline 79 & & & & 0.68 & 0.59 \\
\hline 83 & & & -0.11 & 0.67 & 0.51 \\
\hline 92 & 0.11 & & -0.18 & 0.64 & 0.38 \\
\hline 91 & -0.13 & & -0.17 & 0.63 & 0.38 \\
\hline 81 & -0.10 & & 0.12 & 0.63 & 0.56 \\
\hline 96 & -0.22 & & -0.22 & 0.52 & 0.40 \\
\hline 78 & -0.16 & & 0.19 & 0.50 & 0.68 \\
\hline 54 & & & & 0.49 & 0.70 \\
\hline 76 & -0.10 & & 0.17 & 0.46 & 0.75 \\
\hline 53 & & 0.35 & & 0.43 & 0.71 \\
\hline 95 & 0.37 & & -0.20 & 0.42 & 0.34 \\
\hline 99 & -0.29 & & -0.13 & 0.42 & 0.51 \\
\hline 70 & & 0.11 & 0.12 & & 0.97 \\
\hline 68 & & -0.12 & 0.13 & & 0.96 \\
\hline 69 & -0.15 & & 0.21 & & 0.96 \\
\hline 66 & -0.22 & -0.12 & 0.11 & & 0.94 \\
\hline 58 & -0.20 & & & & 0.93 \\
\hline 67 & -0.25 & & 0.22 & & 0.93 \\
\hline 74 & & & & -0.30 & 0.92 \\
\hline 75 & & & 0.16 & 0.29 & 0.91 \\
\hline 60 & & & -0.41 & & 0.87 \\
\hline 63 & -0.13 & & & -0.41 & 0.87 \\
\hline 62 & -0.26 & -0.12 & -0.36 & 0.13 & 0.83 \\
\hline 59 & -0.12 & & -0.46 & & 0.82 \\
\hline 71 & & -0.30 & & -0.25 & 0.82 \\
\hline 73 & -0.21 & & 0.19 & -0.31 & 0.82 \\
\hline 65 & & -0.14 & -0.35 & 0.26 & 0.82 \\
\hline 61 & -0.13 & & -0.50 & & 0.81 \\
\hline 64 & -0.21 & -0.12 & 0.10 & -0.48 & 0.79 \\
\hline 77 & -0.30 & -0.29 & -0.12 & -0.11 & 0.78 \\
\hline
\end{tabular}

Table 1. Factor loading scores from factor analysis.

After the 99 locations were categorized into larger regions using factor analysis, the time series plot was used to display the temperature pattern in the 4 factor regions. We found that most factors were not situated in the same region. For example, 25 locations representing factor 1 was found between latitudes $20^{\circ}-35^{\circ}$ north while only one location in factor 1 was found in latitudes $30^{\circ}$ south. The same applies to factor 2 as well as 13 locations between latitudes $10^{\circ}-30^{\circ}$ north, one location in the equator and 8 locations between latitudes $10^{\circ}-30^{\circ}$ south.

All factors were displayed using time series plots as shown in Figure 4. Natural cubic spline functions were used to fit the temperature data in each factor. To fit the cubic spline to these data the knots were selected for the spline functions at seven times during each year for factors 1 and 2, and at three times per year for factors 3 and 4 (denoted by + symbols in the graphs). The plots of all factors display clear periodic variation patterns, with peaks at different months of the year. The pattern of temperature in factor 1 was similar to factor 2 and showed higher volatility, especially for factor 1 which had peaked in May and troughs in October in every year. Furthermore, factor 3 was similar to factor 4 and showed a lower variation of temperature, which might reflect climatic variation. In factor 1 and 2, 7 knots equally spaced in each year were found to be appropriate fit. However, in factor 3 and 4,3 knots equally spaced in each year were found to be appropriate fit. The number of knots to fit the data could 


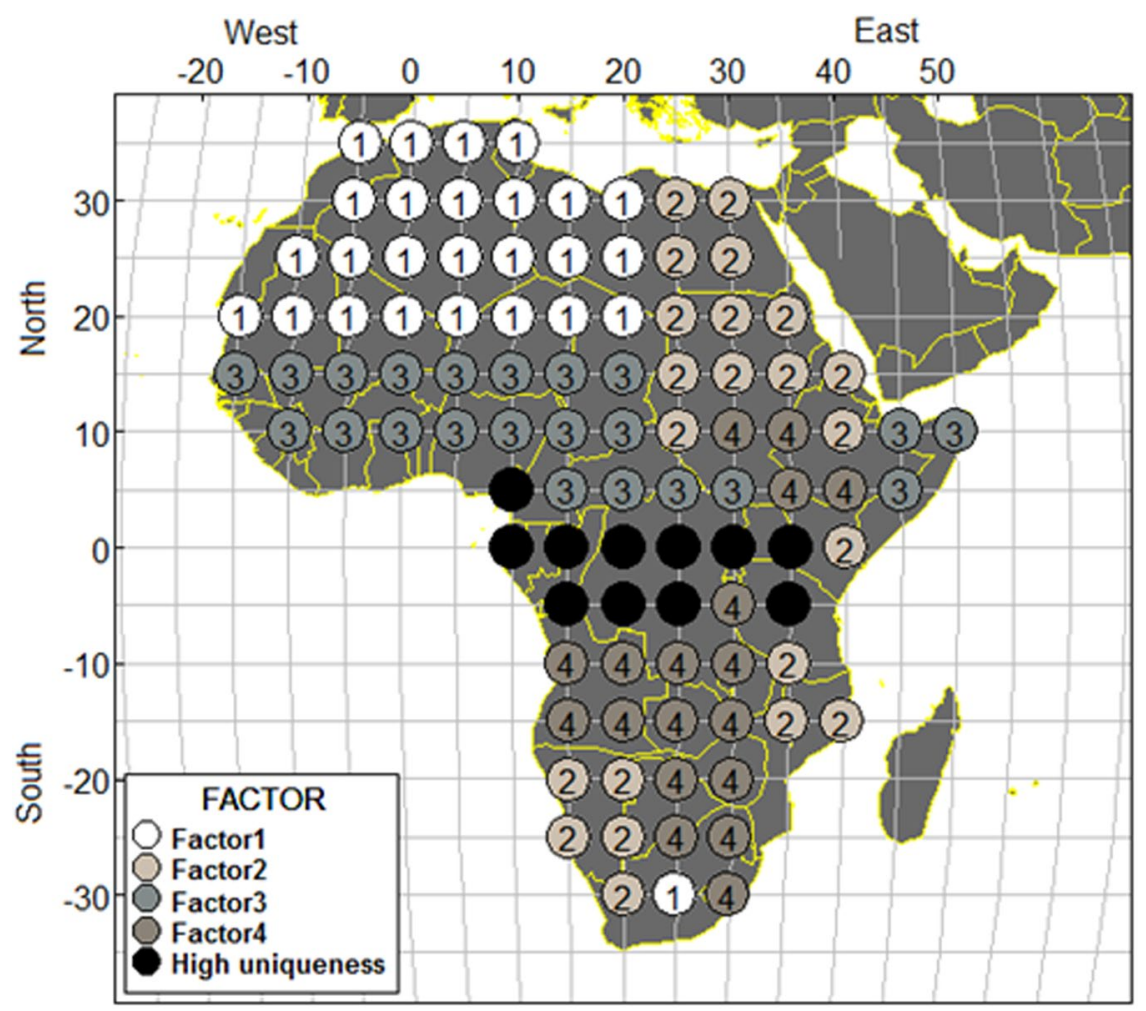

Figure 3. Factor analysis classifying the 99 locations into 4 regions. Numbers in the circles represent the factor number.

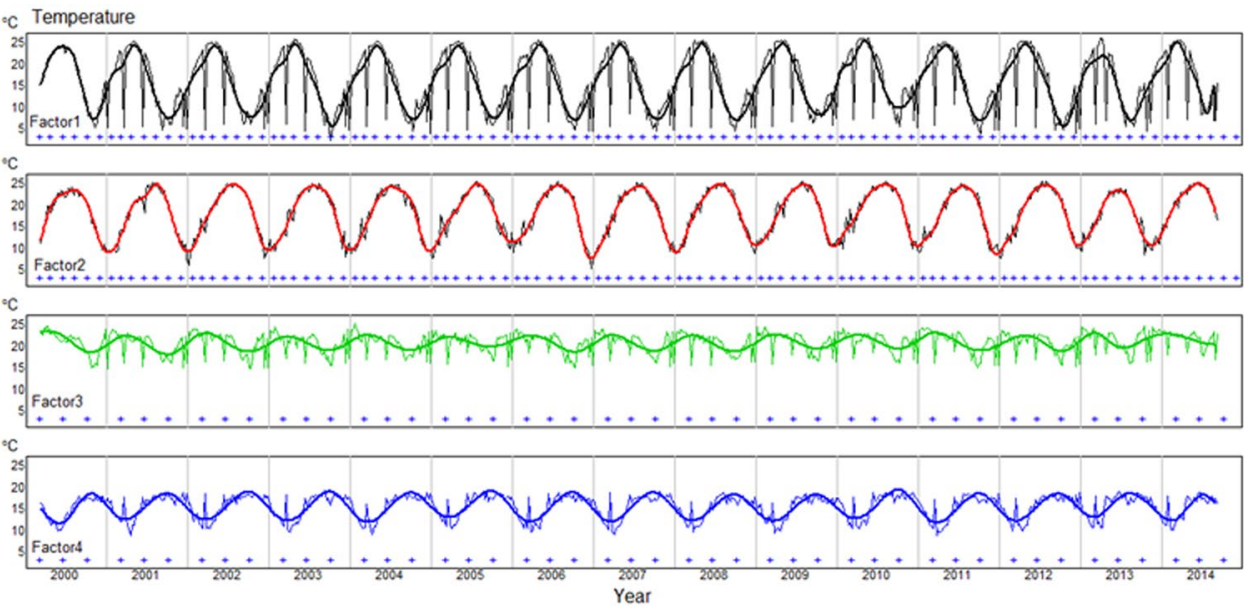

Figure 4. Time series plots of night land surface temperatures for four regions in Africa. The + symbols represent cubic spline knots.

be dependent on the variation of the temperature. More variation of data will require the use of more knots for proper fit and less variation will require the use of fewer knots.

The findings of this study show evidence of temperature variation in the African continent from 2000 to 2014. Temperature changes in the north of Africa were higher than those in the south, These higher changes were mainly in the higher latitudes. This finding was consistent with previous studies ${ }^{21}$. Another study indicated that the northern part of Africa had night time warming in recent years ${ }^{10}$. Moreover, the land areas over the Sahara and semi-arid parts of southern Africa warmed by $1.6^{\circ} \mathrm{C}$ up to $2050 \mathrm{~s}$ and the equatorial African countries warmed at a steady rate of about $1.4^{\circ} \mathrm{C}$ per year ${ }^{22,23}$. The maximum temperatures over Zimbabwe for the period 1897 to 1993 showed a warming trend during all seasons ${ }^{24}$. The rising temperatures observed in the land areas over the Sahara, semi-arid parts of southern Africa and the equatorial African countries may be detrimental to the life of some crops. An increasing temperature may cause yield declines between $2.5 \%$ and $10 \%$ across a 
number of agronomic species throughout the 21 st century ${ }^{25}$. Other investigations on the evaluations of temperature on crop yield have reported varying results, estimates of yield decline between $3.8 \%$ and $5 \%{ }^{26}$.

Temperatures decreased was observed in southern Africa, parts of central Africa, and parts of eastern Africa. The trends of the drop in temperature were also consistent with a other studies ${ }^{10,24}$, the minimum temperatures over Zimbabwe for the period 1897 to 1993 had no trend or a slight decrease. South African maximum temperatures had decreased from 1940 to $1989^{27}$. In our study eighteen locations in central Africa and eastern Africa had both increases and decreases in temperature. The temperatures in these locations are typical of equatorial regions and are influenced by a combination of the region's high altitude and the rain shadow of the westerly monsoon winds.

\section{Conclusions}

Night land surface temperatures for every eight day periods data were studied from 2000 to 2014 for each of 99 locations of $5^{\circ}$ by $5^{\circ}$ latitude-longitude grid-boxes in Africa. Statistical methods comprising linear regression models, time series analysis, factor analysis, and cubic spline were used to investigate the features and classify temperature variability in this study. Analysis of night land surface temperatures for every eight day period found that the temperature increase in 81 locations, 12 locations showed decrease temperature and 6 locations showed no change. The temperature changes ranged from $-0.76^{\circ} \mathrm{C}$ to $1.38^{\circ} \mathrm{C}$. The maximum increase in temperature, approximately $1.38^{\circ} \mathrm{C}$, occurred in the desert area of the North of Africa. The minimum increase temperature, approximately $0.03^{\circ} \mathrm{C}$, occurred in the East of Africa. Factor analysis showed diverse patterns of temperature in the four factors. Natural cubic spline functions were fitted to display the variation pattern in each factor. Even though the observed 15 years temperature trends may not imply climate change, the observe trends and patterns is essential to various stakeholders particularly the agronomist in the planning of the various crop operations.

In this study, only night time observations were investigated in Africa which are considered a critical areas for global warming. Further studies could explore the daytime temperature. We have employed only temperature data without taking into account other factors affecting the variation of temperature. Consequently, different areas and the relationship between the temperature and the other climate factors should also be investigated. The study related land surface temperature changes to land use could also investigate. The techniques presented in this research can be extended to other studies such as rainfall, wind, and solar radiation.

Received: 2 July 2019; Accepted: 29 October 2019;

Published online: 04 December 2019

\section{References}

1. National Academies Report. Understanding and Responding to Climate Change: Highlights of National Academies Reports (2008).

2. Houghton, J. T. et al. Climate change 2001: the scientific basis: contribution of working group 1 to the third assessment report of the intergovernmental panel on climate change. Cambridge University Press, New York (2001).

3. Hughes, L. Climate change and Australia: trends, projections and impacts. Austral Ecology 28, 423-443 (2003).

4. Hulme, M. Regional climate change scenarios based on IPCC emissions projections with some illustrations for Africa. Area 26, 33-44 (1994).

5. Christy, J. R., Norris, W. B. \& McNider, R. T. Surface temperature variations in East Africa and possible causes. Journal of Climate 22, 3342-3356 (2009).

6. Nicholson, S. E. Climatic and environmental change in Africa during the last two centuries. Climate Research 17, 123-144 (2001).

7. Tyson, P. D. Climatic change in southern Africa: past and present conditions and possible future scenarios. Clim Change 18, 241-258 (1991).

8. Hulme, M., Doherty, R., Ngara, T., New, M. \& Lister, D. African climate change: 1900-2100. Climate research 17, 145-168 (2001).

9. Hughes, W. S. \& Balling, R. C. Urban influences on South African temperature trends. Int JClimatol 16, 935-940 (1996).

10. King'Uyu, S. M., Ogallo, L. A. \& Anyamba, E. K. Recent trends of minimum and surface temperatures over Eastern Africa. Journal of Climate 13, 2876-2886 (2000).

11. Wan, Z. \& Dozier, J. A. generalized split-window algorithm for retrieving land-surfacetemperature from space. IEEE Trans Geosci Rem Sens 34, 892-905 (1996).

12. Wan, Z. MODIS land surface temperature products users' guide. Institute for Computational Earth System Science, University of California, Santa Barbara, CA, USA (2006).

13. Venables, W. N. \& Ripley, B. D. Modern Applied Statistics with S. Springer (2002).

14. McNeil, N. \& Chirtkiatsakul, B. Statistical Models for the Pattern of Sea Surface Tempterature in the North Atlantic during 1973-2008. International Journal of Climatology 36(11), 3856-3863 (2016).

15. Owusu, B. E. \& McNeil, N. Statistical Modelling of Daily Rainfall Variability Patterns in Australia. Pertanika Journal of Science and Technology 26(2), 691-706 (2018).

16. Mardia, K. V., Kent, J. T. \& Bibby, J. M. Multivariate Analysis. (Academic Press Inc, London, 1980).

17. Tabachnick, B. G. \& Fidell, L. S. Using Multivariate Statistics. (Allyn \& Bacon, Boston, MA, 2007).

18. Wold, S. Spline functions in data analysis. Technometrics 16, 1-11 (1974).

19. McNeil, N., Odton, P. \& Ueranantasun, A. Spline interpolation of demographic data revisited. Sonklanakarin Journal of Science and Technology 33, 117 (2011).

20. R Development Core Team. R: A language and environment for statistical computing. R Foundation for Statistical Computing, Vienna http://www.R-project.org. Accessed 1 November 2009 (2009).

21. Me-ead, C. \& McNeil, N. Graphical display and statistical modeling of temperature changes in tropical and subtropical zones. Songklanakarin Journal of Science andTechnology 38, 715-721 (2016).

22. Hernes, H. et al. Climate strategy for Africa. CICERO Report 1995:3, University of Oslo (1995).

23. Ringius, L., Downing, T. E., Hulme, M., Waughray, D. \& Selrod, R. Climate change in Africa:issues and regional strategy. CICERO, University of Oslo, Oslo (2996).

24. Unganai, L. S. Surface temperature variation over Zimbabwe between 1897 and 1993. Theory of Applied Climatology 56, 89-101 (1997).

25. Hatfield, J. L. et al. Climate Impacts on Agriculture: Implications for Crop Production. Agronomy Journal 103(2), 351-370 (2011).

26. Lobell, D. B., Schlenker, W. \& Costa-Roberts, J. Climate trends and global crop production since 1980. Science 333(6042), 616-620 (2011).

27. Muhlenbruch-Tegen, A. Long-Term Surface-Temperature Variations in South-Africa. South African Journal of Science 88, 197-205 (1992). 


\section{Acknowledgements}

We are grateful to Emeritus Prof. Don McNeil for providing valuable advice and supervision. We would like to thank to Centre of Excellence in Mathematics, commission on higher Education, Thailand for providing support to this research.

\section{Author contributions}

C.M. and R.M. designed this study, C.M. obtained the data and performed statistical analyses, R.M. contributed to statistical analyses, discussion and interpretation of the results. All authors contributed through to writing and editing the manuscript.

\section{Competing interests}

The authors declare no competing interests.

\section{Additional information}

Correspondence and requests for materials should be addressed to R.M.

Reprints and permissions information is available at www.nature.com/reprints.

Publisher's note Springer Nature remains neutral with regard to jurisdictional claims in published maps and institutional affiliations.

Open Access This article is licensed under a Creative Commons Attribution 4.0 International License, which permits use, sharing, adaptation, distribution and reproduction in any medium or format, as long as you give appropriate credit to the original author(s) and the source, provide a link to the Creative Commons license, and indicate if changes were made. The images or other third party material in this article are included in the article's Creative Commons license, unless indicated otherwise in a credit line to the material. If material is not included in the article's Creative Commons license and your intended use is not permitted by statutory regulation or exceeds the permitted use, you will need to obtain permission directly from the copyright holder. To view a copy of this license, visit http://creativecommons.org/licenses/by/4.0/.

(c) The Author(s) 2019 